Two decades of championing faculty development: Is it worth the effort?

\title{
Rogayah Ja'afar
}

Department of Medical Education, School of Medical Sciences, Universiti Sains Malaysia, Malaysia

\section{ARTICLE INFO}

$\begin{array}{ll}\text { Received } & : 11 / 05 / 2012 \\ \text { Accepted } & : 20 / 09 / 2012 \\ \text { Published } & : 01 / 12 / 2012\end{array}$

\section{KEYWORD}

Faculty development

Professional development

Medical education

Situational analysis

(C) Medical Education Department, School of Medical Sciences, Universiti Sains Malaysia. All rights reserved.

CORRESPONDING AUTHOR: Prof. Dr. Rogayah Ja'afar, Department of Medical Education, School of Medical Sciences, Universiti Sains Malaysia, 1650, Kubang Kerian, Kelantan, Malaysia.

Email: rogayah@kb.usm.my 


\section{Introduction}

The roles of medical teachers have evolved through the years since the time of Hippocrates to the post- Flexner era. In ancient time, medical teachers were considered masters of their craft and taught their students often on a one to one basis as an apprentice. During those early years of medical education, students were expected to emulate their teachers in all aspects. Total respect and devotion to one's teacher were the norm. Today we embrace the newer roles of the teacher as a facilitator of learning and a guide to acquiring new knowledge, skills and attitude. Students are now expected to ask questions and seek explanation from the teachers. The twelve roles of the teacher described by Harden and Crosby in 2000 which range from being a lesson planner, resource developer, information provider, assessor, facilitator as well as a role model for our medical students demand a certain amount of preparation and commitment from the institution as well as the individual faculty members (1). In order for medical teachers to be competent and confident to carry out all these educational roles, they do need to be prepared and trained to carry out the job. Thus faculty development is a fundamental and an integral component of human resource development particularly for medical schools. Jason in 1972 alluded to the complex and important business of creating doctors (2). He questioned the preparation of those responsible to carry out this task as almost negligible.

He then further argued that instruction alone is the special work of and indeed the reason for the existence of medical schools and that other activities such as research and patient care, while important, can be performed elsewhere (2).

\section{Definition of Faculty Development}

Faculty development encompasses in its broadest sense a structured program in which specific activities are offered to help faculty members to develop their capacity to become more efficient and effective teachers as well as to carry out other aspects of their multifaceted academic roles such as contributing to administrative and managerial activities, conducting research as well as writing and presenting publishable materials (2). At the institutional level, faculty development should be seen as a tool for improving the academic vitality of our medical schools by paying attention to the competencies needed by our individual faculty members and to our institutional policies required to promote their academic excellence (3).

\section{Situational Analysis}

The School of Medical Sciences (SMS) Universiti Sains Malaysia (USM) is a relatively new medical school following an innovative curriculum. Thus the focus of our faculty development activities is for a major part, directed towards that one activity that is uniquely related to being a faculty member i.e. teaching (4). In the early days of medical education, teaching expertise was assumed to be part of or even synonymous with content expertise.

Over time, teaching has come to be recognised as a skill associate with, but separate from, content expertise. The success of such efforts would aid both teachers and learners: by helping the former to derive a greater pleasure from their instructional responsibilities and the latter to attain more positive attitudes and higher achievement (5). Indeed areas that have frequently been voiced by both faculty and students as in need of attention by the Department of Medical Education (DME), point to that direction. Some of the areas identified by our faculty members through our regular needs assessment survey for faculty development include:

- orientation of new staff and students to the philosophy of SMS;

- orientation of students to the purpose and methods of problem centred learning;

- developing teachers' skills in facilitating problem-based learning groups;

- $\quad$ the study of group dynamics and developing teacher's skills in group dynamics;

- $\quad$ preparation of learning materials for problem packages;

- the use of newer methods of students assessment; 
- development of a format for teacher evaluation, and helping teachers utilize feedback from such evaluation;

Other staff development activities geared towards meeting needs and/or solving problems unique to SMS would include:

- helping faculty members use the numerous formal meetings in the school, in a more effective and efficient manner;

- orientation of students and teachers to the concept of self-directed learning, and thus assisting students to fully utilized their selfstudy schedules.

- assisting faculty in student selection and matching their follow up performance in medical school

- preparing teachers, administrative staff and students for curriculum review exercises

Faculty development was identified as one of the major responsibilities of the DME since the Medical School's inception in 1981. The first faculty development workshop on Problem Based Learning was carried out in 1986. Since then, a yearly faculty development program with a series of six to eight workshops are run annually on various topics in medical education such as curriculum planning, teaching learning approaches, student assessment methods and program evaluation. In planning and implementing the yearly planner of faculty development activities, the Medical School is guided by the following principles and rationale:

1. There is a body of knowledge which is justifiably described as educational sciences;

2. It follows logically that health profession educators should be familiar with that science and skilled in its application;

3. Since that science gives promise of increasing both educational effectiveness as well as economizing in the use of scarce resources (particularly teacher time and student time), it is worthy of systemic application;

4. There is widespread evidence of serious deficiencies in present educational practices, some of which can be corrected by training teachers in the sound application of educational principles;

5. The growing interest of faculties of medicine and of other health professions in such training strongly suggests that individual teachers and administrators find the results personally satisfying or professionally rewarding. (For example in some medical schools, a medical teaching component is now required to be included in accredited post-graduate training in a medical specialty).

6. The increasing array of practitioners, auxiliaries and students who participate in the instruction of health profession students makes some kind of training programme essential.

(Extracted from the report of a WHO study group on the training and preparation of teachers for medical schools and of allied health sciences, Geneva, 1973). During the formative years of SMS when it was forging an active campaign to recruit local and young academic staff, the DME had to tailor its faculty development activities according to the different stages of personal and career development of individual faculty members. The department's efforts were mainly geared towards ensuring that each individual teacher became advanced as a person with improved skills in helping others to learn (6).

Newly appointed staff would be more concerned with establishing their competence in their own fields. Teaching is likely to become a concern at this stage only so far as teaching ability reflects knowledge of the subject matter (7). Accordingly, the major efforts of the department would at this stage in time, be directed towards practical assistance in the areas in which the teacher recognizes a need, as in the preparation of instructional materials, planning and preparation of lectures as well as the setting and marking of examinations (6).

As the teachers reached a state of satisfaction with their academic standing and professional development, the DME began to strive to channel their energy and interest beyond the mechanics of teaching into the actual process of education and the examination of innovations 
and areas of improvement. The primary role of the department at this stage would be one of continued awareness raising particularly the awareness that intrinsic rewards exist in teaching, of provision of resources which indicate the broader view of educational problems as they are encountered and of adviser to those concerned with faculty governance (6, 7). In addition to helping individual faculty members improve their own teaching, attention was also directed towards the dynamics of organizational behavior especially those related to introducing and evaluating change, the exposure of academic staff to experiential groups and a development of their skills in understanding and facilitating group interactions.

While these two efforts were fundamental and are currently continued on a regular basis, attention must subsequently be turned towards the development of a concern for continuing improvement of the total academic programme of the medical school. This took the form of a formative evaluation of the different phases of the medical programme and ultimately led to a summative evaluation of the whole programme through an 'on the job' assessment of its first batch of graduates in 1986 and a series of comprehensive evaluation of the undergraduate medical curriculum since 1996. To date we have undertaken four curriculum reviews of our undergraduate MD program and is currently in the midst of the fifth major curriculum revision and development.

In an effort to provide a comprehensive and effective faculty development programme, a number of faculty development models were studied and the model proposed by Bergquist and Philip (1975) was adopted (8). The proposed model is based on the assumption that significant changes must take place at three levels:

a) attitudes;

b) process;

c) structure; for successful faculty development.

An effective faculty development programme must deal with the attitudes of the faculty members as well as with interrelated values, philosophies and self perception. It must address attention to the process of instruction such as instructional methods and technology, curriculum development and student evaluation of instruction. Finally the programme must anticipate and deal with the structural constraints of the organization within which the faculty operates. These basic assumptions concerning structure, process and attitudes have been translated by the authors, in graphic form to a model of faculty development.

A critical decision for any faculty development program occurs when an entry point into the system is identified. The most appropriate and least threatening of these entry points is probably faculty interviews. Critical decision points are also often found in the movement from one component or aspect of the programme to another. Though all of the components should be defined at the start of a faculty development program, they should be publicly introduced only when they seem to be appropriate from the perspective of the participants in the programme. Thus, components such as personal growth and departmental team building should not receive high visibility at the start of a faculty development program, but should instead emerge as the participating faculty members recognize the needs for these services (8).

In an effort to improve our faculty development program, an evaluation questionnaire is administered at the end of each faculty development activity. Through the years, we find that generally the faculty members appreciate and learn something new from all our workshops. They do bring back new ideas and information to colleagues in their respective departments and there is subtle evidence that improvements are being introduced across departments. However, many workshop participants voice a desire and need for post workshop (more long term) support to sustain their motivation and commitment for new ideas and innovation. 


\section{Challenges, Triumphs and Tribulations}

One of the major challenges for the DME faculty is the frustration of seeing a never ending rapid turnover of academic staff members in the medical school. The DME has run more than 200 faculty development activities since 1986 and more than 4,000 faculty members have attended these workshops over the years. In the formative years, when we had to recruit teaching faculty from overseas, these expatriate teachers tended to leave when their children reached the age of twelve as there was only a single international school catering for primary level education in the state. Now a day, the brain drain is the result of the higher salary schemes offered by private hospitals and private medical colleges to entice our young local lecturers into their sectors. As a result of this continuous rapid turnover of staff, lecturers who attend our workshops get good at teaching, and then we lose them to others.

While this phenomena is common and not only typical of USM, having to run the programme over and over again, tires and ties the Department down quite a bit. Another pitfall with faculty development is the persistent need to persuade and counter argue with the more senior faculty members about the need to call everyone to the table to look at problems and their potential solutions. While most faculty members tend to agree and participate, there will be a number of resisters who would be sceptical and often scorn change and renewal with excuses such as "We have been teaching this way for the past 30 years - why change now?" (9). Then, there are the opinion leaders who watch both the innovators and resisters closely and show shrewd timing in giving their approval to the innovation, in the hope of getting recognised for their "just in time" decision. It is really awesome how much we can achieve, if we do not care who gets the credit. Thus it is vital to recognise the different attitudes of our colleagues and to respond accordingly (10). On the other hand, we get very excited each time when we receive positive feedback from our workshop participants and particularly our own students that they benefited from our efforts at faculty development and curriculum renewal. Often, when we aspire for changes in our curriculum, we need to put the burden on ourselves to start that process. We carry out pilot and demonstration projects and evaluate these projects. When a project works and the students like what we are doing, then the faculty will listen and know that the change is possible. So we find that if we have struggled with the new initiative ourselves, the faculty will be much more willing to listen to us. If the faculty feels that we are part of the team and are making the changes together with them, they are more likely to make and sustain changes.

For example, if we want to encourage innovation such as the use of contract learning in our community based medical education program, we not only have to run faculty development activities dealing with contract learning and the role of supervisors, we also had to become one of the supervisors. This way when people talked to us about their problems, we can appreciate their issues because we have dealt with them and have gone through the same process. We therefore talk on the same wavelength! (9)

\section{Conclusion}

In conclusion, faculty development is an integral and fundamental component of human resource development at the SMS, a medical school which has consciously adopted and followed an innovative as well as a challenging undergraduate medical education programme. We do need to sustain the faculty development programme in order to sustain the momentum of innovation. To ensure that this programme achieves its objectives and makes a difference in the training of doctors it is imperative that support and commitment at the highest level is guaranteed. Perhaps the following sentiment by Bergquist sums up the whole conceptual framework and ideal for effective faculty development: 'A comprehensive faculty development programme is certainly not a parttime responsibility for one faculty member or administrator, nor is it a programme that can be carried out exclusively with volunteer help.' 
'A faculty development programme begun with serious intent must be adequately staffed by professionals, with additional support provided by other available campus resources, including both faculty and students.' (8)

\section{Reference}

1. Harden RM, Crosby J. Changing teacher roles, Medical Teacher, 2000; 34: 334-347.

2. Jason $\mathrm{H}$ and Westberg J. Teachers and Teaching in U.S. Medical Schools, chapters 19 and 20, Connecticut, Appleton-CenturyCrofts, 1982.

3. Wilkenson LA, Irby DM. Strategies for Improving Teaching Practices: A Comprehensive Approach to Faculty Development, Academic Medicine, 1998; 73 (4): 387-396.

4. Rotem A, Cox KR and Bennett MJ. Faculty Development: proceedings of the WHO RTTC intercountry workshop, University of New South Wales, Sydney, 4-16 Feb. 1979.

5. Stritter FT. Faculty Evaluation and Development. In Mc. Guire,C.. et al, (Ed.) Handbook of Health Professions Education, San Francisco, Jossey-Bass, 1983.

6. Rogayah J. A Plan for the Functioning of the Department of Medical Education at the School of Medical Sciences, Universiti Sains Malaysia, Major Project Report in Partial Fulfillment of the degree of MHPEd, University of New South Wales Press, 1986.

7. Cox KR, Garrick CE, Bandaranayakee R, Bennett MJ and Rotem A. Teaching Teachers, PLET, 1980; 17 (2): 72-76.

8. Berquist WH and Philips SR, Components of an Effective Faculty Development Programme, Journal of Higher Education, 1975; XLV1 (2): 177-209.

9. Jane Westberg. Making A Difference: An Interview of Rogayah Binti Ja'afar, Education for Health, 2000: 13 (2): 237-243.

10. Cox K. Persuading Colleagues to Change: Fifteen Lessons Learned from More than 20 Years of Trying, Education for Health, 1999; 12 (3): 347-353

\section{Additional Readings}

1. Rogayah J. Monograph on Faculty Development at the School of Medical Sciences, Universiti Sains Malaysia, $3^{\text {rd }}$ Edition, 2011 